\title{
ENVOI FROM THE EDITOR AND A WELCOME TO THE NEW PUBLISHER AND EDITOR
}

Dear Friends and Colleagues,

In 1987, with the strong support of a distinguished editorial committee, we founded this journal, putting out the first issue in the autumn of 1988. It has continued with very few changes in the editorial board right up to volume 33, while expanding greatly in size and coverage and with the most recent issues printed in full colour. Key to its longevity has also been the support of many friends and colleagues who took out subscriptions from the earliest days. Many experts worldwide have gladly offered advice and recommendations when called upon, purely out of their commitment to the field and to high-quality scholarship. In the process they spared JRA from countless errors, even as we quickly came to realise that it is impossible to eliminate all mistakes from a project of this size. Our debts extend to thousands who joined the cause to sustain an untraditional venture. And here the editor must express his apologies to any authors or would-be contributors who have felt or indeed have been mistreated: an editor's job is rarely easy as a multitude of factors impinge upon each decision, and he knows that he has made mistakes.

From the outset, JRA was intended to be an international journal that extended to the farthest reaches of the empire and even beyond (as seen in the current issue). It would be presumptuous to think that a field such as Roman archaeology could be properly covered and adequately represented by native English-speakers alone: this was not to be a journal about Roman archaeology as practiced by those who happened to have been born in anglophone lands. For this reason we were always willing to entertain articles and reviews written in French, German, Italian and Spanish; equally, we have been willing to work intensively with non-anglophone scholars who preferred that their work appear in English. And we have encouraged young scholars to publish their work here. A second guiding principle was that $J R A$ should embrace all the specialties (epigraphy, numismatics, mosaics, sculpture, pottery, glass, architecture, urban development, field survey, demography, to name just a few) within the broader field of archaeology. It would not look down upon or exclude any subdiscipline and would try to give space to important work of all kinds and to different approaches. No less, it intended to position itself at the intersection of archaeology and history, to show how historical problems impinge upon the work and interpretations of archaeologists and how the work of archaeologists can inform the work of historians: ancient texts are not all there is for historians to work with. In recent decades the two disciplines have been drawing closer together, not least in the areas of social and economic history and thanks to innovative work being done in the hard sciences.

Having started a family business of this kind, we quickly became conscious of our responsibility to secure its future as we came to learn how much it was being valued by our audience. To this end, a few years ago we began to explore the possibilities with a number of institutions. After careful thought, in 2019 we determined that Cambridge University Press was the publisher best placed to continue to fulfill JRA's mission, where it would be handled alongside our sister journals JRS, PBSR and Britannia. With this editor having arrived at or even surpassed a customary retirement age, we were pleased to sign an agreement with CUP on July 20, 2020. Starting with volume 34 (2021), $J R A$ will be published on behalf of the Press Syndicate of the University of Cambridge: see https:// www.cambridge.org/core/news/journal-of-roman-archaeology-acquired-by-cambridge-universitypress. The annual will be edited by Dr. Jennifer Trimble, Associate Professor of Classics at Stanford University, a highly respected scholar whom the present editor has known since our time together at the University of Michigan.

The present volume (33) and all back issues (1-32) will continue to be handled by Laura Humphrey at jra@JournalofRomanArch.com until January 1, 2021; thereafter, orders for the annual journal should go direct to CUP. We ourselves will still publish a few more supplements which are already in process, and orders for all of the 109 volumes in that supplementary series should continue to be placed with us at jra@journalofromanarch.com for 2-3 more years. Subsequently, CUP plans to digitize the complete run of $J R A$ supplements.

The editor feels privileged to have worked closely with so many scholars of so many different nationalities over the past 33 years, learning an enormous amount in the process. Now he would like to assure future contributors that their work will be in good hands and that the long-term future of the journal itself is assured.

August 3, 2020

John Humphrey editor
Laura Humphrey

business manager
Leah Humphrey

website manager

95 Peleg Road, Portsmouth, Rhode Island 02871, USA 